\title{
Three Schools of Paraconsistency
}

\author{
KOJI TANAKA* \\ Philosophy Department, Macquarie University \\ Koji.Tanaka@mq.edu.au \\ Received by Greg Restall \\ Published July I, 2003 \\ http://www.philosophy.unimelb.edu.au/ajl/2003
}

(C) 2003 Koji Tanaka

\begin{abstract}
A logic is said to be paraconsistent if it does not allow everything to follow from contradictory premises. There are several approaches to paraconsistency. This paper is concerned with several philosophical positions on paraconsistency. In particular, it concerns three 'schools' of paraconsistency: Australian, Belgian and Brazilian. The Belgian and Brazilian schools have raised some objections to the dialetheism of the Australian school. I argue that the Australian school of paraconsistency need not be closed down on the basis of the Belgian and Brazilian schools' objections. In the appendix of the paper, I also argue that the Brazilian school's view of logic is not coherent.
\end{abstract}

But though logic has come a long way very recently, it has a longer way to go, both in whom it involves and what it investigates. There are, for instance, virtually no black researchers, and exceedingly few women are engaged; and for all the proclaimed rationality of modern humans and their institutions, logic touches comparatively little human practice. Differently, there remain many notions of considerable logical import, some of historical significance, of which we lack decent accounts or, sometimes, a clear appreciation. To the satisfactory elucidation of these, sociative logics can make essential contributions.

$$
\text { Sylvan (1989) p. I33. }
$$

\section{INTRODUCTION}

A logic is said to be paraconsistent if it does not allow everything to follow from contradictory premises: it is not the case that for any $\alpha$ and $\beta$,

${ }^{*}$ I would like to thank Graham Priest for making some of the ideas contained in the paper clear and for his comments on drafts of the paper. I would also like to thank Diderik Batens, Otávio Bueno and Newton da Costa for their comments on a draft of the paper. A draft of the paper was presented at the 1998 Australasian Association for Logic Conference held at Macquarie University in Sydney. Many thanks go to the members of the audience. 
$\{\alpha, \neg \alpha\} \models \beta$ (ex contradictione quodlibet: $\mathrm{ECQ}$ ). There are several approaches to achieve this end, as is surveyed by Priest and Routley (1989a) and Priest and Tanaka (1996). This paper surveys several philosophical positions on paraconsistency. In particular, the paper concerns three 'schools' of paraconsistency: Australian, Belgian and Brazilian.1 Arguably the most radical school, the Australian school of paraconsistency, led by Priest and Sylvan (né Routley), claims that there are some true contradictions and that the logic is paraconsistent. (Sylvan did however advocate logical pluralism in a posthumously published work, Sylvan (1997).) The Belgian school, led by Batens, and the Brazilian school, led by da Costa, argue against the Australian school. They question the existence of true contradictions. More importantly, they not only reject the idea that the logic is paraconsistent but also deny that there is a uniquely correct logic. I argue that their objections are based on misinterpretation of the claim of the Australian school and/or are unsuccessful. I conclude then that the Australian school need not be closed down on the basis of the Belgian and Brazilian schools' objections. Moreover, in the appendix of this paper, I argue that the Brazilian school's view of logic is not coherent. ${ }^{2}$

\section{Schools of Paraconsistency}

If we put aside the 'forerunners', the first paraconsistent logic was developed by a Polish logician Jaśkowski (1948). His approach was to not allow premises to be adjoined: $\{\alpha, \neg \alpha\} \not \forall \alpha \wedge \neg \alpha$. This non-adjunctive approach has remained in the Polish school of paraconsistency ${ }^{3}$ The non-adjunctive approach has also been advanced by the Canadian school of paraconsistency ${ }_{4}^{4}$

After its inception, the development of paraconsistent logics has been car-

${ }^{\mathrm{I}}$ As was pointed out by a number of my colleagues, referring to schools of paraconsistency in terms of geography is not appropriate. For the ideas held by paraconsistent logicians are not bound by geographical borders. However, the schools described herein are 'typified' by practitioners within each respective country, and I therefore take the labels to be illuminating and at least partially descriptive.

${ }^{2}$ Parts of the paper can be seen to deal with the issue of logical monism and logical pluralism. However, I do not touch upon that issue for two reasons. Firstly, the contemporary debates between logical monists and logical pluralists are recent phenomena. The rigorous debates between them started with an explicit formulation of logical pluralism and a rejection of logical monism by the Australian logicians Beall and Restall (2000). This paper was written well before the publication and even the explicit formulation of their position, and hence I was unable to benefit from the debates between logical monism and logical pluralism. Secondly, the issue that I am concerned with in this paper is not that of the debate between logical monists and logical pluralists in general. It is rather the objections to the Australians that have been raised by the Belgians and the Brazilians. Dealing with the issue of logical monism vs. logical pluralism takes us beyond the scope of the paper.

${ }^{3}$ See Perzanowski (1997) for the Polish school of paraconsistency.

${ }^{4}$ For example, Jennings and Schotch (198I) and Schotch and Jennings (I980). The nonadjunctive approach was also taken up by the Americans, Rescher and Manor (1970) and Rescher and Brandom (I979). 
ried out in many different places 5 Arguably the most radical approach has been taken up by the Australian school of paraconsistency. The major roles have been played, among others, by Priest and Sylvan who claim that there are true contradictions. They argue that because of the existence of true contradictions, logic must be paraconsistent ${ }^{6}$ This dialetheic approach has raised eyebrows among many people including many paraconsistent logicians. The Belgian school, led by Batens, has objected to the claim that logic must be paraconsistent. The Brazilian school, led by da Costa, has questioned the claim that there are true contradictions and also rejected the idea that logic must be paraconsistent.

\section{Logic and Logical Systems}

Before examining the Belgian and Brazilian schools' objections to the Australian school, an important issue in the philosophy of logic needs to be addressed. That is the distinction between LOGIC and logical systems.

Now, I would be, quite correctly, accused of being absurd if I were to defend the view that the theory of dynamics is itself moving entities.7 The theory of dynamics is an explanation and description of moving entities. Explanation and description are not themselves moving entities. As Restall (1994) puts it:

The general theory of relativity may describe the Way the World Is in a clear and perspicuous way, it may fit the facts, or be ideally useful, or maximally coherent, or whatever - but it isn't to be identified with what it is intended to describe. (p. II)

There is no need to elaborate on this issue any further.

However, it is not clear at all whether the point is widely taken when the topic is logic. It is in fact a common confusion in logic not to distinguish a theory from entities which are described by it, where the theory in question is a logical system which has mathematical properties, and the entity is LOGIC 8 In advancing a pragmatist conception of logic, Haack (1996) describes a logic (i.e., a logical system) as a theory:

logic [i.e., a logical system] is a theory, a theory on a par, except for its extreme generality, with other, 'scientific' theories ... (p. 26)

Haack does not mention LOGIC in her discussion. Yet, just as in the theory of dynamics, a logical system must not be confused with LOGIC. For a logical system is a theory of LOGIC and hence it is not itself LOGIC.

\footnotetext{
${ }^{5}$ See Arruda (1989) and Priest and Routley (1989b).

${ }^{6}$ Not all of the Australian paraconsistent logicians hold this view. In this paper, I am only concerned with the approach taken by Priest and Sylvan.

${ }^{7}$ The example is taken from Priest (1987), as will be clear later on.

${ }^{8}$ What the nature of LOGIC is, is an interesting question. However, I leave the entire question for another occasion, except that LOGIC can be thought of as a truth-maker of a logical system.
} 
The story is not as simple as it is presented above. In the case of science, there is no dispute that there are some entities that a theory describes. Even if one is not a scientific realist, no one seriously argues that the theory of dynamics is itself moving entities. Now in the case of logic, it is not uncommon to reject the existence of LOGIC. For, unlike moving entities, LOGIC is not anything material. The logical instrumentalist argues that there is nothing that a logical system corresponds to. For them, the study of logic is no more than that of internal properties of logical systems such as the systems' algebraic properties. None the less, the logical instrumentalist does not claim that a logical system is LOGIC. They simply do not accept the existence of LOGIC. If one is a realist about logic, whether a monist or a pluralist, and so believes in LOGIC or LOGICS, then the difference between LOGIC and a logical system must be apparent. That a logical system is not itself LOGIC is now well established.

\section{4 ... and the Australian School of Paraconsistency}

The Australian school of paraconsistency takes seriously the distinction between LOG IC and logical systems and argues against classical logic. They argue that classical logic is a theory. Since it is a theory, the idea that classical logic could not even be questioned must be rejected. As the history of science tells us, a theory may be shown to be false at a later time regardless how well the theory is entrenched. Priest (1987) writes:

No one needs to be told that one needs to distinguish between our theory of dynamics and moving bodies themselves. One is an attempt to provide a correct theoretical explanation for, and description of, the other, and to confuse the two is absurd. Yet a similar confusion is common in logic. The fact that we use the same word, 'logic', for both is but an effect (rather than a cause) of this. But just as with dynamics, so with logic, one needs to distinguish between reasoning, or better, the structure of norms that govern valid/good reasoning, which is the object of study, and our logical theory, which tries to give a theoretical account of this phenomenon. The theoretical principles we do actually accept are not God-given and fixed for all time. Indeed, reasoning is a complex and delicate human activity, and it is unlikely that any theory we produce, at least for the present, and maybe for ever, cannot be improved. The norms themselves may also change. There may well occur a dialectical interaction, characteristic of the social sciences, between the object of the theory and the theory itself. None the less, the distinction between a science and its object remains; and once this gap is opened, it suffices for the fallibility of any theory. (pp. 257-258) 
Restall (1994) uses exactly this thesis of Priest to meet Quine's famous objection that changing the logic is changing the subject.9 Based on the distinction between LOG IC and logical systems, then, the Australian school of paraconsistency argues that classical logic must be rejected as a false theory.

The problem that the Australian school points out is that classical logic fails to capture LOGIC properly. In order for a logical system to do so, it has to encapsulate truth-preservation in all situations, as Priest (1999a) argues. What situations need to be considered and how large the realm of LOGIC is, are the questions that invite hot disputes, as Haack (1978) demonstrates. The Australian school of paraconsistency argues that all situations, whether consistent or not, need to be considered $\sqrt{\mathrm{IO}}$ For, Priest (1987) and Routley (I980) argue in their discussions on semantic paradoxes and set theoretic paradoxes, the realm of LOGIC includes inconsistent situations. Yet classical logic fails to capture truth-preservation in inconsistent situations.

However, Priest (1989) argues that the use of classical logic is acceptable in some situation if there are good reasons to assume that the situation is consistent. For him, consistent situations have a peculiar (LOG ICal) structure and classical logic accommodates this peculiar structure. This does not mean that paraconsistent logics do not capture the structure. Classical logic can be seen as a special case of paraconsistent logics: classical logic can be 'recaptured' from a paraconsistent perspective $]^{m}$ The recapture demonstrates that the peculiar structure is well within the reach of paraconsistent logics. None the less, classical logic fails in inconsistent situations. Hence Priest (and Sylvan) argues that the "universality of classical logic must be rejected" ${ }^{12}$

Since logic is about truth-preservation in all situations, therefore, paraconsistent logic should be accepted, at least tentatively, as a correct logical theory instead of classical logic. For some evidence shows that it is paraconsistent logic that accommodates all situations and hence captures LOGIC properly. Thus Priest and Sylvan argue for the universal validity of paraconsistent logics. ${ }^{13}$ Whether this Australian school's claim is ultimately defensible or not, I do not pursue in this paper. Instead, I will consider some objections to the Australian school. Those objections have been put forward by the Belgian and Brazilian schools of paraconsistency.

\footnotetext{
${ }^{9}$ Quine's objection is found in Quine (1970).

${ }^{10} \mathrm{~A}$ paraconsistent logician may be concerned with not only inconsistent situations but also incomplete situations. As issues surrounding contradictions are the subjects of this paper, incomplete situations need not concern us here.

${ }^{\text {II }}$ See Priest (2002) for the classical recapture. Mortensen (1995) argues that classical mathematics is a special case of paraconsistent mathematics.

${ }^{\text {I2 }}$ Priest (1987) p. 257.

${ }^{13}$ See especially the appendix of Routley (1980) titled 'Ultralogic as Universal?' where Ultralogic means one particular paraconsistent logic. See also Mortensen (1983) for his defense of the non-validity of Disjunctive Syllogism which supports the claim made by Priest and Sylvan.
} 


\section{5 ... And the Brazilian School of Paraconsistency}

The clearest statements of the Brazilian school's objections to the Australian school are found in da Costa and Bueno (1996). They argue that the views of the Australian school of paraconsistency are fallacious. Their argument is that paraconsistent logic is not the true logic on the basis that any logic may be false. However, their objections to the Australian school are based on a mis-conception of the philosophy of the Australian school.

In comparing classical logicians and non-classical logicians, i.e., Australian paraconsistent logicians, da Costa and Bueno reject the idea that paraconsistent logic is the true logic. They write:

Instead of claiming, with the older «radical» proposals, that classical logic is a tool to apprehend the most general structure of the world (it is supposed to be true after all!), their new «radical» version [i.e., the Australian school of paraconsistency] claims the same as far as certain non-classical logics are concerned. One wonders, in such a case, about the meaning of learning from experience - that is, from the recent history of logic. Indeed, what is the import, the relevance of this history, with the changes and moves that it has yielded, to our philosophical understanding of logic? Given these circumstances, how not to be fallibilistic after all? (pp. 53-4)

This complaint seems misguided, at face value. As we saw previously in the writing of Priest, the Australian school advances a fallibilistic view that classical logic is a false theory.

One may argue, however, that the Australian school is not fallibilist about paraconsistent logics. In this sense, the Australian school is the same as the school of classical logicians. Yet this is to misunderstand the claim made by the Australian school. What they are advancing is a fallibilistic view of any theory. Their view is not that of the dogmatist. They do not dogmatically hold that paraconsistent logics are true theories. Their fallibilistic view of logical theory includes the fallibility of paraconsistent logics. Based on their analysis of several issues, the Australian school claims that it is paraconsistent logics, not classical logic, that should be embraced. For, given the currently available data, paraconsistent logics solve the problems that they consider, such as semantic paradoxes and set theoretic paradoxes. None the less, they admit that they could be wrong, as paraconsistent logics are theories.

The mistake that the Brazilian school makes is not only that they take the Australian school to be dogmatic but also that they take the Australian school to be claiming that logic is "stable" ${ }^{[4}$ Kant thought that logic was a completed science. He held the view that logic "contains merely the form of thought" and that the laws of logic are "the conditions of the use of the understanding in

${ }^{\mathrm{I} 4} \mathrm{da}$ Costa and Bueno (I996) passim. 
general" ${ }^{15}$ Based on these views, Kant argued that logic could not be altered.

There are two things that have to be said about the Brazilian school's claim. Firstly, a logical system is a theory for the Australian school. Since it is a theory, a logical system could be altered in order to accommodate new evidence. For example, one may decide to eliminate some classically accepted rules of inference. This is how substructual logics, some of which are paraconsistent, were developed ${ }^{16}$ Secondly, the Australian school does not argue that LOGIC is stable. We have seen Priest arguing that the norms that govern reasoning may change. There is no argument to the effect that LOGIC does not change over time.

Thus, objections put forward by the Brazilian school of paraconsistency to the Australian school are based on a mis-conception. Whether or not the philosophy of the Australian school, properly understood, is defensible, is another matter. None the less, da Costa and Bueno's objections can now be put aside.

\section{6 ... and the Belgian School of Paraconsistency}

The Belgian school of paraconsistency is concerned with the Australian school's claim that LOGIC is unique. They argue that there are several LOGICs each of which has its domain ${ }^{17}$ Consequently, they argue that there are several logical systems that are correct. In objecting to the Australian school, the Belgian school proposes contextualism. Batens (1990) writes:

I think there is another alternative [to the Australian approach] for which there are good independent arguments, viz., 'contextualism'. The idea is that we do not depend on a fixed global system, which should be justified once and for all, but that we set up a specific context (involving meanings, relevant data, methodological instructions, etc.) whenever we meet a problem. (p. 226)

That there is an alternative is not sufficient to reject the Australian approach. In fact, contextualism is not in general incompatible with the Australian approach. For an analogy, consider the case of geometry. It is often said that different geometries are appropriate for different contexts. For example, when we build a house, it is appropriate to use Euclidean geometry. But when we do surveying, it is appropriate to use spherical geometry. And when we do astronomy, it is appropriate to use Riemannian geometry. However, it may be the case that GEOMETRY is unique and that the above three geometries capture it in only some situations. Some factors may safely be ignored when a geometry is applied to a different context. The same may be true of logic. As we saw earlier, the Australian school argues that paraconsistent logics and classical logic

\footnotetext{
${ }^{15}$ Kant quoted in Haack (1996) p. 27 and p. 28 respectively.

${ }^{16}$ For an introduction to substructual logics, see Restall (2000).

${ }^{17}$ The Brazilian school seems to hold a similar view. But their view is not as clear as that of the Belgian school.
} 
collapse into each other in a consistent (and complete) situation in the sense that both paraconsistent and classical logic capture the consistent (and complete) part of LOGIC. The acceptance of the use of classical logic in consistent (and complete) situations does not interfere with LOGIC being paraconsistent as a whole. Hence the Belgian approach is not necessarily incompatible with the Australian approach, as far as logical systems are concerned. But based on contextualism, Batens puts forward another objection.

Batens takes to heart the Australian school's claim that the correct logic is the one which captures the logical aspects of all situations. Despite the Australian school's claim, he argues that paraconsistent logics are too weak to be applied to consistent situations. Batens (1989) writes:

If applied to consistent sets of premises, ... paraconsistent logics lead to proofs that are considerably poorer. (p. 190)

Specifically, he argues that there is some 'context' in which paraconsistency fails ${ }^{18}$ Batens (1990) writes:

The metalinguistic description of classical negation is beyond the reach of paraconsistency, and so is classical triviality. (p. 227)

In order to analyse Batens' objection, we need to be clear about what he means by a context. He defines it in Batens (1985) as follows

What I mean by 'a context' is precisely a communication situation. A context is characterized by (i) a set of participants, (ii) the problem that one tries to solve, (iii) the set of statements that are regarded as certain and in this sense define the set of possible answers to the problem, (iv) the set of aspects that are considered relevant to the problem, and (v) the set of methodological do's and don'ts that are judged appropriate with respect to the problem. (p. 334)

Based on this definition, Batens argues that each context has its own LOGIC and a LOGIC in one context may not be the same as a LOGIC of another context.

Now the context that is beyond the reach of paraconsistency, that Batens has in mind, seems to be the one in which 'negation' is expressed in terms of 'classical negation', which we denote by $\sim{ }^{20}$ Let's call this context $c$. Then Batens' objection is that the negation operator of, for example, Priest's logic LP (I979), which we denote by $\neg$, is too weak for context C. Thus the LOGIC of $c$ is not paraconsistent, at least not LP.

\footnotetext{
${ }^{18}$ Parsons (I990) raises a similar point.

${ }^{19}$ Batens (1985) is mainly concerned with the philosophy of science. But Batens (1992) claims that his contextualism is substantiated in logic, and Batens (1985) presents a contextual philosophy of logic towards the end of the paper.

${ }^{20}$ In the literature on relevant logics, $\sim$ is called Boolean negation.
} 
The Batens objection may appear intuitive, since $\sim$ and $\neg$ are prima facie incompatible with each other ${ }^{27}$ Yet its justification is hard to come by. Since it is a classical negation, $\sim$ is defined as follows: $\sim \alpha$ is true iff $\alpha$ is not true. This definition satisfies the law of non-contradiction, the law of excluded middle, and so on. On the other hand, $\neg$ is defined as follows: $\neg \alpha$ is true iff $\alpha$ is false. If we assume that a formula cannot be neither true nor false, this definition also satisfies the law of non-contradiction, the law of excluded middle, and many other laws of classical logic, as Priest (I999b) demonstrates. Moreover, if inconsistency (and incompleteness) is rejected ${ }^{22}$ this definition will be equivalent to that of $\sim$. For, in this case, if $\alpha$ is not true then it is false, and vice versa. Hence $\sim$ and $\neg$ behave in the same way. In particular, $\sim$ and $\neg$ are identical in context c. Thus, if $\sim$ captures the negation fragment of LOGIC of $c, \neg$ does the same.

Still, Batens argues that $\neg$ is weaker than $\sim$ in context $c$. He claims that $\neg$ cannot be used to express the exclusion of $\alpha$ by $\neg \alpha$ and vice versa. Batens (I990) argues that if negation is expressed by $\neg$,

[a sentence asserted] does not rule out the sentence that is negated and is intended not to rule this out. (p. 223)

Indeed, the fact that $\alpha$ and $\neg \alpha$ both may be true seems to show that expressing exclusion is beyond the reach of $\neg$.

But how is the exclusion expressed in classical logic? The definition of does not do the job. For if $\alpha$ is both true and not true then both $\alpha$ and $\sim \alpha$ are true. According to Batens (1990), the exclusion is expressed in terms of ECQ, and ECQ is the only way to express it. For, by adopting ECQ

Someone who asserts $\sim \alpha$ is truly committed to the rejection of $\alpha$ : asserting $\alpha$ as well would commit one to triviality. (p. 222. The logical symbols are mine.)

On the other hand, a paraconsistent logic, such as LP, Batens argues, does not allow us to "express correctly that we reject some sentence" (pp. 222-3). For asserting both $\alpha$ and $\neg \alpha$ does not lead to triviality ${ }^{23}$

\footnotetext{
${ }^{21}$ Of course, $\sim$ and $\neg$ are 'compatible' in the sense that they can both occur in the same logic, as is shown by Meyer and Routley (1973) and Meyer and Routley (1974). But the discussion here is concerned with the question of whether or not $\neg$ is too weak for some context.

${ }^{22}$ Then non-primeness (a theory $\Sigma$ is non-prime iff for some sentences $\alpha$ and $\beta, \alpha \vee \beta \in \Sigma$ but $\alpha \notin \Sigma$ and $\beta \notin \Sigma)$ is also rejected. For primeness follows from consistency and completeness (given De Morgan's laws). See Mortensen (1983) pp. $37 \mathrm{f}$.

${ }^{23}$ The same objection is applicable to a theory of belief revision whose underlying logic is paraconsistent. Batens (1980) argues that "only those theories are informative that "forbid" something". (p. 227) Yet in a theory whose underlying logic is paraconsistent, "no sentence will ever lead to the rejection" (p. 23I). So if we use a belief set to represent one's beliefs and use a paraconsistent logic as an underlying logic, then there is nothing in the theory of belief revision that commits us to revise our beliefs. In reply to this problem, even if one rejects ECQ and so there is no logical reason to revise our beliefs, when the beliefs become incoherent, one may revise their beliefs. See Tanaka (1995) and Tanaka (1998) for this line of reply. And beliefs being
} 
It is not clear whether the exclusion of $\alpha$ by its negation is an element of the realm of LOGic. The exclusion may be presupposed as a norm that governs reasoning in some context. If a context is a communication situation, we may agree to exclude something by asserting its negation. In other words, the exclusion can be a feature of a logical system as a theory that we use in some context. Yet it is questionable whether the exclusion is part of the 'structure of norms' which seems to be what the Australian school takes LOGIC to be, as can be seen from Priest quoted above. Just as it is absurd to argue that the structure of a building is itself the building, it does not seem reasonable to suppose that the structure of norms is itself a norm. Even if it is argued that the exclusion is part of LOGIC, ${ }^{24}$ there is no reason why paraconsistent logicians cannot introduce into the language of the logical system an absurdity constant, $\perp$ (or $f$ ), and let it be governed by a rule $\perp \vdash \beta$ for all $\beta$. In order to express the exclusion of $\alpha$ by $\neg \alpha$, one may further introduce the rule $\{\alpha, \neg \alpha\} \vdash \perp$. In this way, asserting both $\alpha$ and $\neg \alpha$ leads to triviality. In effect, thus, we have ECQ. Therefore, that $\alpha$ rules out $\neg \alpha$ can be expressed paraconsistently as in classical logic, despite the claim made by Batens.

It may be argued that what ECQ encapsulates is the functionality of evaluations of formulas. If an evaluation is a function, every formula is assigned either true or false, but never both (and never neither). So, it may be argued, what expresses the exclusion of $\alpha$ and its negation is the definition of $\sim$ together with the functionality of evaluations. And paraconsistent logics, in particular, LP whose evaluation of a formula is a relation instead of a function, do not capture the spirit of the exclusion, although they can introduce some rules in order to 'imitate' its effect.

None the less, the exclusion can be expressed in a paraconsistent logic with the introduction of the two rules mentioned above. If the exclusion is an element of LOGIC and so has to be captured by a logical system as a theory, the rules serve to express the exclusion in the system. Of course, we need to debate what is the best way to express it. The functionality of evaluations of formulas together with the definition of $\sim$ may well give rise to a 'better' theory. In any case, the fact that the exclusion can be expressed paraconsistently undermines Batens' claim that paraconsistent logics are too weak to be applicable in some context.

To sum up: we have considered the Batens objection that there is some context in which paraconsistency fails, in particular, $\neg$ is weaker than $\sim$. However, it does not seem that Batens has made his case.

incoherent may have nothing to do with logic. There may be many a posteriori reasons why beliefs are incoherent. See Priest (200I) for an account of belief revision which is based on this idea.

${ }^{24}$ Note that if the exclusion is not an element of the realm of LOGIC, classical logic, that has that element, does not capture LOGIC properly. 


\section{Summary}

I have argued that the objections raised by the Belgian and Brazilian schools of paraconsistency to the Australian school are not well founded. This is not to argue that the Australian approach is justified. There may be legitimate objections that could not be rejected. None the less, the Brazilian school's objection is based on a mis-conception of the Australian school. And the Belgian school's objection is not successful. Thus the Australian school need not be closed down on the basis of Belgian and Brazilian schools' objections.

\section{Appendix}

Having dismissed the Belgian and Brazilian schools' objections to the Australian school, let's now carefully examine the Brazilian school's view of logic. ${ }^{25}$ It does not seem that their view is coherent.

\section{I Agnosticism, Pluralism and the Brazilian School of Para- CONSISTENCY}

In advancing agnosticism in the study of logic, da Costa and Bueno (1996) reject the notion of 'true logics'. They write:

If they [viz., applied logics] are to be minimally successful, perhaps our «radical» might claim, they have to be true, at least as far as their domains are concerned. This is an interesting remark. The problem underlying it, as in general with any radical view, consists in supplying evidence to the claim that such logics are in fact true. No means though seem to be available to offer such an evidence (there seems to be a considerable underdetermination at this level). (p. 55)

Both the classical school and the Australian school of paraconsistent logic have independently given some evidence as to why their logic is the true logic, although they argue for different logics on the basis of different evidence. Unless da Costa and Bueno can successfully reject the evidence given by these schools, their argument can hardly be taken seriously.

Moreover, da Costa and Bueno argue that a logic has its particular domain:

... an all-embracing logic, appropriate to all domains is hard to find. We are thus in general left with (several) alternative logics that describe only some aspects of them, and there are many heuristic and pragmatic reasons to choose between such logics, de-

\footnotetext{
${ }^{25}$ The following consideration is not applicable to the Belgian school. In this appendix, I
} consider only the Brazilian school. 
pending in particular, of course, on the specific traits found in such domains. (p. 54)

However, if it is a problem to supply evidence to justify a logic being true, it must also be a problem to provide heuristic and pragmatic reasons for the claim that a logic has its own domain. For, unlike the instrumentalist, da Costa and Bueno do not ignore the realm of LOG IC completely. Da Costa and Bueno are required to provide some reasons why it is 'this' logic instead of 'that' logic that has this particular domain. Hence they have to be concerned with the true logic for each domain. However, that is the concern that they identify as a problem in the study of logic.

None the less, it is not clear whether the Brazilian school subscribes to realism or instrumentalism. ${ }^{27}$ On the one hand, they reject realism by not being concerned with LOGIC in their study and development of logic. On the other hand, they reject instrumentalism by considering 'domains' which are the realm of LOGIC. It may be possible to establish a middle ground between the two. ${ }^{28}$ Yet their view of logic has not been well enough articulated to do so. It seems that the Brazilian school's view of logic is not very coherent.

\section{REFERENCES}

Arruda, A.I. (1989) 'Aspects of the Historical Development of Paraconsistent Logic', Paraconsistent Logic: Essays on the Inconsistent, G. Priest, R. Routley, and J. Norman (eds.), Philosophia Verlag, München, pp. 99-I30.

Batens, D. (1980) 'Paraconsistent Extensional Propositional Logics', Logique et Analyse, Vol. 23, pp. 195-234.

Batens, D. (1985) 'Meaning, Acceptance, and Dialectics', Change and Progress in Modern Science, J.C. Pitt (ed.), Dordrecht, D. Reidel Publishing Company, pp. 333-36o.

Batens, D. (1989) 'Dynamic Dialectical Logics', Paraconsistent Logic: Essays on the Inconsistent, G.Priest, R.Routley and J.Norman (eds.), Philosophia Verlag, München, pp. I87-2I7.

Batens, D. (1990) 'Against Global Paraconsistency', Studies in Soviet Thought Vol. 39, pp. 209-229.

\footnotetext{
${ }^{26}$ They continue: "Thus the relativist threat, based on the claim that there are no criteria of choice between rival logics, can be at least in part circumvented" (p. 54). However, the relativist does not claim that there are no criteria of choice. It is just that the criteria are relative to some factors. Thus it is not clear how da Costa and Bueno do not count as relativists.

${ }^{27}$ Priest (2000) points out that da Costa (1997) is confused about realism and instrumentalism.

${ }^{28}$ For example, Detlefsen (1986) takes Hilbert's programme to lie between realism and nominalism (instrumentalism).
} 
Batens, D. (1992) 'Do We Need a Hierarchical Model of Science', Inference, Explanation, and other Frustrations: Essays in the Philosophy of Science, John Earman (ed.), Berkeley, University of California Press, pp. 199-215.

Beall, J.C. and G. Restall (2000) 'Logical Pluralism', Australasian fournal of Philosophy, Vol. 78, pp. 475-493.

da Costa, N. C. A. (1997) Logiques classiques et non classiques, Masson, Paris.

da Costa, N. and O. Bueno (I996) 'Consistency, Paraconsistency and Truth (Logic, the Whole Logic and Nothing but 'the' Logic)', Ideas $y$ Valores, No. I0o, pp. 48-60.

Detlefsen, M. (1986) Hilbert's Program: an Essay on Mathematical Instrumentalism, D. Reidel Publishing Company, Dordrecht.

Haack, S. (1978) Philosophy of Logics, Cambridge University Press, Cambridge.

Haack, S. (1996) Deviant Logic, Fuzzy Logic, The University of Chicago Press, Chicago.

Jaśkowski, S. (1948) 'Rachunek zdah dla systemów dedukcyjnych sprzecznych', Studia Societatis Scientiarun Torunesis, Sectio A, Vol. I, No. 5, pp. 55-77, reappeared as 'Propositional Calculus for Contradictory Deductive Systems', Studia Logica, Vol. XXIV, pp. I43-157.

Jenning, R.E. and P.K. Schotch (I98I) 'The Preservation of Coherence', Studia Logica Vol. XLIII, I/2, pp. 98-I06.

Meyer, R. and R. Routley (1973) 'Classical Relevant Logics', Studia logica, Vol. 3I, pp. 5I-68.

Meyer, R. and R. Routley (1974) 'Classical Relevant Logics II', Studia logica, Vol. 33, pp. I83-194.

Mortensen, C. (1983) 'The Validity of Disjunctive Syllogism Is Not So Easily Proved', Notre Dame fournal of Formal Logic, Vol. 24, pp. 35-40.

Mortensen, C. (1995) Inconsistent Mathematics, Kluwer Academic Publishers, Dordrecht.

Parsons, T. (1990) 'True Contradictions', Canadian fournal of Philosophy. Vol. 20, pp. 335-353.

Perzanowski, J. (1997) 'Parainconsistency or Inconsistency Tamed and Investigated', a paper read to the First Congress on Paraconsistency, Gent.

Priest, G. (1979) 'The Logic of Paradox', fournal of Philosophical Logic, Vol. 8, pp. 219-24I. 
Priest, G. (1987) In Contradiction: a Study of the Transconsistent, Martinus Nijhoff Publishers, Dordrecht.

Priest, G. (1989) 'Reductio ad Absurdum et Modus Tollendo Ponens', Paraconsistent Logic, Essays on the Inconsistent, G. Priest, R. Routley and J. Norman (eds.) Philosophia Verlag, München, pp. 613-626.

Priest, G. (I999a) 'Validity', The Nature of Logic (European Review of Philosophy, Volume 4), A. Varzi (ed), CSLI, Stanford.

Priest, G. (I999b) 'What Not? A Defence of Dialethic Theory of Negation,', What is Negation?, D.M. Gabbay and H. Wansing (eds.), Kluwer Academic Publishers, Dordrecht, pp. IOI-I2O.

Priest, G. (2000) 'Review of 'N.C.A. da Costa Logiques classiques et non classiques', Studia Logica, Vol. 64, pp. 435-443.

Priest, G. (200I) 'Paraconsistent Belief Revision', Theoria, Vol. 67, pp. 2I4-228.

Priest, G. (2002) 'Paraconsistent Logic', Handbook of Philosophical Logic (Volume 6, Second Edition), D. Gabbay and F. Guenthner (eds.) Kluwer Academic Publishers, Dordrecht, pp. 287-393.

Priest, G. and R. Routley (1989a) 'Systems of Paraconsistent Logic', Paraconsistent Logic: Essays on the Inconsistent, G. Priest, R. Routley and J. Norman (eds.), Philosophia Verlag, München, pp. I5I-I86.

Priest, G. and R. Routley (1989b) 'First Historical Introduction: a Preliminary History of Paraconsistent and Dialethic Approaches', Paraconsistent Logic: Essays on the Inconsistent, G.Priest, R.Routley and J.Norman (eds.), Philosophia Verlag, München, pp. 3-75.

Priest, G. and K. Tanaka (1996) 'Logic, Paraconsistent', Stanford Encyclopedia of Philosophy (http://plato. stanford.edu/), Centre for the Study of Language and Information, Stanford University, Stanford.

Quine, W.V.O. (I970) Philosophy of Logic, Prentice-Hall, Englewood Cliffs.

Rescher, N. and R. Brandom (1979) The Logic of Inconsistency, Rowman and Littlefield, NJ.

Rescher, N. and R. Manor (1970) 'On Inference from Inconsistent premisses', Theory and Decision, Vol. I, pp. I79-217.

Restall, G. (1994) On Logics without Contraction, Ph.D Thesis, University of Queensland.

Restall, G. (2000) An Introduction to Substructural Logics, Routledge, London. 
Routley, R. (1980) Exploring Meinong's fungle and Beyond, Research School of Social Sciences, Australian National University, Canberra.

Schotch, P.K. and R.E. Jennings (I980) 'Inference and Necessity', fournal of Philosophical Logic, Vol. 9, pp. 327-340.

Sylvan, R. (1989) Bystanders' Guide to Sociative Logics, Research School of Social Sciences, Australian National University, Canberra.

Sylvan, R. (1997) Transcendental Metaphysics, The White Horse Press, Cambridge.

Tanaka, K. (1995) Paraconsistent Belief Revision, Honours Thesis, University of Queensland.

Tanaka, K. (1998) 'What Does Paraconsistency Do? The Case of Belief Revision', The Logica Yearbook 1997, T. Childers (ed.), Filosophia, Praha, pp. I88-I97. 
The Australasian fournal of Logic (ISSN I448-5052) disseminates articles that significantly advance the study of logic, in its mathematical, philosohpical or computational guises. The scope of the journal includes all areas of logic, both pure and applied to topics in philosophy, mathematics, computation, linguistics and the other sciences.

Articles appearing in the journal have been carefully and critically refereed under the responsibility of members of the Editorial Board. Only papers judged to be both significant and excellent are accepted for publication.

The journal is freely available at the journal website at

$$
\text { http://www.philosophy.unimelb.edu.au/ajl/ }
$$

All issues of the journal are archived electronically at the journal website.

SUBSCRIPTIONS Individuals may subscribe to the journal by sending an email, including a full name, and email address and a postal address to the managing editor at ajl-editors@unimelb.edu.au Subscribers will receive email abstracts of accepted papers to an address of their choice. For institutional subscription, please email the managing editor at ajl-editors@unimelb.edu.au

Complete published papers may be downloaded at the journal's website at http: //www.philosophy.unimelb.edu.au/ajl/ The journal currently publishes in pdf format.

Submission The journal accepts submissions of papers electronically. To submit an article for publication, send the $\mathrm{LT}_{\mathrm{E}} \mathrm{X}$ source of a submission to a member of the editorial board. For a current list of the editorial board, consult the website.

The copyright of each article remains with the author or authors of that article. 